\title{
Pain Management and Opioid Therapy: Persistent Knowledge Gaps Among Primary Care Providers
}

\author{
Chad Williamson' \\ Barbara J Martin ${ }^{2}$ \\ Charles Argoff ${ }^{3}$ \\ Christopher Gharibo ${ }^{4}$ \\ Bill McCarberg ${ }^{5}$ \\ Timothy Atkinson ${ }^{6}$ \\ Leanne Berger' \\ Thomas Sullivan' \\ 'Rockpointe, Columbia, MD, USA; \\ ${ }^{2}$ Independent Consultant Physician/ \\ Writer, Lancaster, PA, USA; ${ }^{3}$ Albany \\ Medical College, Albany, NY, USA; \\ ${ }^{4} \mathrm{New}$ York University School of \\ Medicine, New York City, NY, USA; \\ ${ }^{5}$ University of California, San Diego, CA, \\ USA; 'Veteran's Administration \\ Tennessee Valley Healthcare System, \\ Nashville, TN, USA
}

Correspondence: Chad Williamson Rockpointe, 1760 Russet Hill Circle, Hoover, AL, 35244, USA

$\mathrm{Tel}+\mathrm{I}-205-266-5568$

Email cwilliamson@rockpointe.com
Introduction: Given the opioid epidemic in the US, it is vital that clinicians who prescribe opioids for pain management to do so in an evidence-based manner, eg considering all pharmacologic and non-pharmacologic options, assessing risk of opioid use disorder prior to initiating opioids. Continuing education regarding the evidence-based prescribing of opioids is now required for US healthcare providers who prescribe opioids. A "blueprint" of the content to be included in continuing education programs was developed by the US Food and Drug Administration and updated in 2018.

Methods: To understand the baseline knowledge and confidence of healthcare professionals in prescribing opioids for pain management, we posed 27 unique knowledge-based questions and 1 confidence question to clinician participants before or during 2 continuing educational programs that were based respectively on the 2016 and 2018 FDA Risk Evaluation and Mitigation Strategy (REMS) educational blueprints for pain management.

Results: Overall, 5571 clinicians completed these programs, including 1925 physicians (1516 [79\%] identifying as primary care), 1181 physician assistants, 737 advanced practice nurses, 719 nurses, and 479 pharmacists. Responses to pretest questions in both programs indicated profound and persistent gaps in knowledge, particularly in definitions and mechanisms of pain, general principles of pharmacologic analgesic therapy, and specific aspects of opioid analgesic therapy and addiction. Participants in both programs also expressed limited confidence in their abilities to incorporate patient engagement techniques into pain management or develop a treatment plan for a patient with chronic pain.

Discussion: These data support an ongoing need for comprehensive clinician-based education as outlined in the FDA REMS educational blueprint, especially given recent data of escalating overdose deaths during the COVID-19 pandemic.

Keywords: analgesics, opioid, chronic pain, pain management, opioid-related disorders, primary health care, continuing medical education, CME, risk evaluation and mitigation strategy, REMS

\section{Introduction}

Opioid misuse, abuse, and overdose remain prominent public health crises in the United States. National statistics indicate that nearly 47,000 Americans died of opioid overdoses in 2018, increasingly through the use of heroin and synthetic opioids like fentanyl and its analogues. ${ }^{1}$ Yet approximately two-thirds of opioid-related deaths are due to the misuse of prescription opioids. ${ }^{2}$ In addition, approximately 1.7 million Americans experience substance use disorders related to prescription opioids. ${ }^{2,3}$ The Centers for Disease Control and Prevention (CDC) estimate that the economic burden of prescription-opioid misuse alone costs the United States $\$ 78.5$ billion annually, 
which is represented in healthcare expenses, lost productivity, addiction treatment, and criminal justice costs. The latest US overdose data, which extend into the beginning of the COVID-19 pandemic, reveal the highest number of drugoverdose deaths ever recorded during a 12-month period (81,000 from May 2019-May 2020). In that same time frame, 37 of 38 US jurisdictions reported increases in synthetic opioid-involved overdose deaths. ${ }^{4}$

The American opioid crisis is the unfortunate result of several converging factors, including the high prevalence of chronic pain, the development and aggressive marketing of a number of newly available prescription opioids in the 1990s, the underestimated risk of addiction with opioids, and the rapidly escalating prescription rate of these opioids over the ensuing years in an effort to manage chronic pain. $^{2,5,6}$ At the beginning of the 21 st century, concerted efforts were made specifically to raise awareness of the undertreatment of pain. These efforts included the establishment of pain-management standards by the Joint Commission on Accreditation of Healthcare Organizations and the designation of the 2000s as the "Decade of Pain Control and Research" by Congress. ${ }^{7,8}$ The unintended results of these efforts were the widespread misuse and diversion of prescription opioids, before it became abundantly clear that they had the potential to be extremely addictive. Primary care prescribers have been at the unfortunate forefront of the opioid crisis, owing to their traditional gatekeeping positions within the healthcare system. Physician groups accounting for the highest opioid prescriptions are family medicine $(20.5 \%)$ and internal medicine $(15.7 \%){ }^{9}$ Nurse practitioners and physician assistants account for approximately $10 \%$ and $9 \%$ of opioid prescriptions, respectively. Family medicine physicians and medical internists also make up a significant proportion of the top tenth percentile of high prescribers of opioids. ${ }^{10}$

In July 2012, the Food and Drug Administration (FDA) approved the Extended-Release (ER) and Long-Acting (LA) Opioid Analgesic Risk Evaluation and Mitigation Strategy (REMS) to ensure that the benefits of opioid analgesics used in the outpatient setting outweigh the risks. To further address the misuse and abuse of prescription opioids and to promote the judicious prescription of opioid analgesics, the FDA approved the FDA Blueprint for Prescriber Education for Extended-Release and LongActing Opioid Analgesics in 2016. ${ }^{11}$ This blueprint stipulated that all companies producing or selling ER or LA opioid analgesics financially support ongoing certified continuing education (CE) for all health care providers who manage pain. The blueprint also outlined core educational messages for industry-funded CE activities, including the assessment and counseling of patients, the initiation and management of opioid therapy, and information about opioid analgesics. The FDA blueprint was modified in 2018 to include the use of immediate-release (IR) prescription opioids. Specifically, the FDA drafted and published its Education Blueprint for Health Care Providers Involved in the Treatment and Monitoring of Patients with Pain. ${ }^{12}$ The 2018 FDA blueprint identified a need for comprehensive pain education, in which all pain management options are considered. The blueprint further stipulated that health care practitioners should have information about the risks of opioid use and misuse and should be able to create opportunities for patient counseling and other methods to reduce risks. The blueprint then laid out the clinical core educational messages to be addressed in a comprehensive pain education program. These core messages addressed broad categories of instruction that encompass assessments of pain, the use of comprehensive and multimodal management, and the recognition of opioid misuse and addiction.

In an effort to identify educational gaps in pain management and the prescription and monitoring of opioids among primary care providers, Rockpointe, a continuing medical education (CME) company, conducted pretest polling questions before and during 2 of its certified $\mathrm{CE}$ programs that were designed to adhere to and address the core educational messages outlined by the 2016 or 2018 FDA blueprint.

\section{Methods}

The responses to pretest polling questions were collected and analyzed from 2 Rockpointe-sponsored certified CME/ CE programs that were based on the 2016 and 2018 FDA blueprints, respectively: "Extended-Release and LongActing Opioid Analgesics: Risk Evaluation and Mitigation Strategy" (Program 1); and "Opioid Analgesics: Risk Evaluation and Mitigation Strategy" (Program 2). Content for these programs was provided to participants through a combination of formats, including live in-person meetings, live webinars, and enduring web courses. Content for Program 1 was based on the 2016 FDA blueprint and provided through 8 live in-person regional meetings at the PainWeekend meetings in 2018, 1 live in-person symposium at the 2018 PainWeek annual meeting, and 1 enduring web course at Medscape 
(medscape.com) during 2018 and 2019. Content for Program 2 was based on the 2018 FDA blueprint and provided through 12 live in-person regional meetings and 4 live webinars, as well as 3 live in-person presentations at the 2019 Medical Education Exchange (MEDX) CME conferences. Pretest questions were formulated by program faculty and $\mathrm{CME} / \mathrm{CE}$ staff and addressed the clinical core educational messages in the 2016 or 2018 FDA blueprint. Responses to pretest questions were recorded by either an audience response system (in the case of live inperson meetings) or through web-based software. Content for the questions and $\mathrm{CME} / \mathrm{CE}$ programs was overseen and approved by a steering committee of faculty members who are experts in pain management. Accreditation of CME/ CE content was provided by the University of North Texas Health Science Center in Fort Worth or the University of South Florida Health in Tampa. Grant support was provided by the REMS Program Companies (RPC). Given that responses analyzed were gathered as part of an accredited educational program and not a direct study of physician practice, and that all responses were anonymous, the retrospective analysis was exempt from review by an institutional review board (IRB).

\section{Results}

\section{Healthcare Disciplines of Participants}

For Program 1, a total of 842 participants completed the regional meetings, 100 participants completed the symposium, and 3372 participants completed the enduring web course. For Program 2, 778 participants completed the regional meetings or live webinars, and 479 participants completed the MEDX conferences. A breakdown of participant completers of the programs is provided in Table 1. In all cases, the number of pretest participants exceeded those of $\mathrm{CME} / \mathrm{CE}$ completers.

\section{Results of Pretest Questions by 2018 FDA REMS Clinical Core Educational Message}

A total of 27 unique pretest knowledge-based questions were presented to participants during CME/CE Programs 1 and 2 . Responses to these questions are categorized by the clinical core educational messages of the 2018 FDA blueprint.

\section{Definitions and Mechanisms of Pain}

An initial core educational message in the 2018 FDA blueprint is the definition of pain and its mechanisms,
Table I Participant Completers of Opioid REMS CME/CE Programs

\begin{tabular}{|l|r|r|r|}
\hline $\begin{array}{l}\text { Participant } \\
\text { Completers }\end{array}$ & $\begin{array}{r}\text { Program I } \\
\text { N = 43 I4 }\end{array}$ & $\begin{array}{r}\text { Program 2 } \\
\text { N = I 257 }\end{array}$ & $\begin{array}{r}\text { All } \\
\text { N = 557 I }\end{array}$ \\
\hline Physician & $1409(33 \%)$ & $516(41 \%)$ & $1925(35 \%)$ \\
\hline Primary care* & $1274(90 \%)$ & $242(47 \%)$ & $1516(79 \%)$ \\
\hline $\begin{array}{l}\text { Advanced } \\
\text { practice nurse }\end{array}$ & $439(10 \%)$ & $298(24 \%)$ & $737(13 \%)$ \\
\hline $\begin{array}{l}\text { Physician } \\
\text { assistant }\end{array}$ & $1101(26 \%)$ & $80(6 \%)$ & $1181(21 \%)$ \\
\hline Pharmacist & $702(16 \%)$ & $316(25 \%)$ & $479(9 \%)$ \\
\hline Nurse & $400(9 \%)$ & $30(2 \%)$ & $430(8 \%)$ \\
\hline Other & & $17 \%)$ & $719(13 \%)$ \\
\hline
\end{tabular}

Note: *Family medicine or internal medicine.

including the biological significance of pain, the relationship between acute and chronic pain, and the distinction between nociceptive and neuropathic pain. The 3 questions and responses addressing this core educational message are shown in Figure 1. In Program 1, only a minority of pretest participants (37\%) recognized an important feature of chronic pain. In Program 2, an even smaller percentage $(12 \%)$ of participants were able to identify examples of nociceptive pain.

\section{Assessing Patients in Pain}

According to the 2018 FDA blueprint, elements of assessment include patient history, screening tools for risks of chronic pain, queries of state prescription drug monitoring programs, pain and functional assessment scales, physical examination, and family, psychological, and social planning. The 2 questions and responses addressing this core educational message are shown in Figure 2. In both programs, a large majority of pretest participants $(95 \%$ and 96\%) recognized the importance of assessing functional outcomes.

\section{Components of an Effective Treatment Plan}

Essential components of an effective treatment plan include the establishment of treatment goals (including functional goals), possible constituents of a treatment plan (including pharmacologic and nonpharmacologic interventions), and a cooperative multidisciplinary 

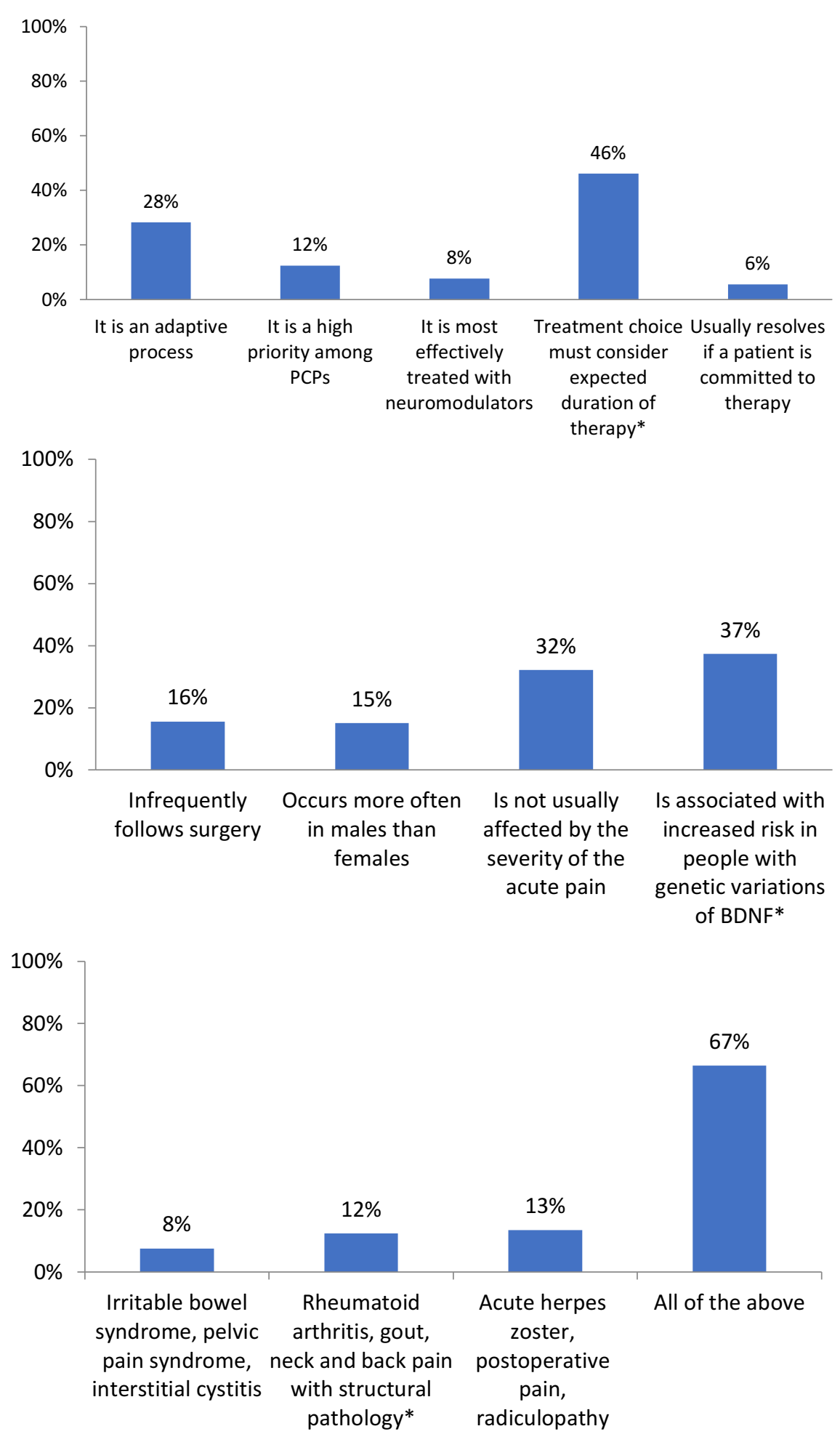

Figure I Pretest questions and responses addressing definitions and mechanisms of pain. (Best evidence-based answers are noted with an asterisk.). Program I: Which of the following statements is true about chronic pain? $(n=4453)$. Program I: Which of the following statements defines chronic pain? $(n=3900)$. Program 2: Examples of nociceptive pain include which of the following? $(n=815)$.

approach with active patient engagement. In Program 1, nearly three-quarters of participants $(73 \%)$ recognized the goal of an effective treatment plan (Figure 3). However, about half (49\%) identified multimodal polypharmacy as the most effective and safe treatment plan. The pretest response to a similar question in Program 2 was substantially higher at $94 \%$. In the same program, effective treatment goals of acute pain were recognized by $61 \%$. 

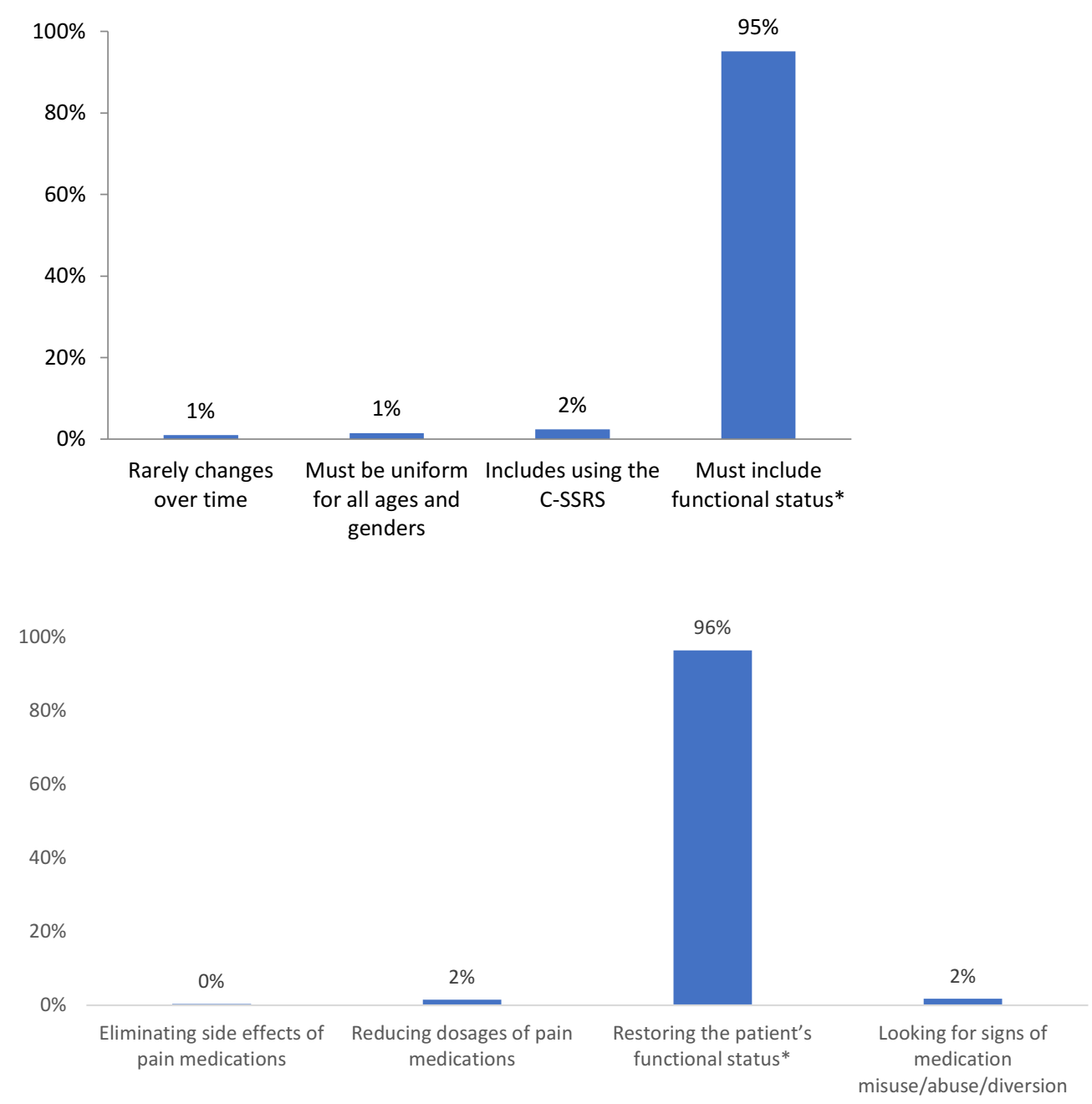

Figure 2 Pretest questions and responses addressing assessments of patients in pain. (Correct answers are shown with an asterisk). Program I: Assessing patients in pain: $(n=3445)$. Program 2: When assessing patients in pain, the main focus should be on: $(n=798)$.

\section{General Principles of Nonpharmacologic Approaches}

Nonpharmacologic and self-management treatment options in the 2018 FDA blueprint include psychological, physical rehabilitative, and surgical approaches, as well as the use of approved medical devices for pain management. In both programs, a sizeable majority ( $70 \%$ and $74 \%$, respectively) identified interventional approaches as acceptable components of nonpharmacologic therapies for pain (Figure 4).

\section{General Principles of Pharmacologic Analgesic Therapy}

This core message of the 2018 FDA blueprint includes information about opioid and non-opioid analgesics, including mechanisms of action, pharmacokinetics, formulations, and dosing. In Program 1, a minority of pretest participants demonstrated knowledge of opioid interactions or metabolism (Figure 5). In Program 2, only about onequarter of participants identified correct pharmacokinetic or pharmacogenetic features of relevant medications.

\section{Managing Patients on Opioid Analgesics}

The 2018 FDA blueprint outlines educational messages for the use of opioids, including the initiation of treatment for acute or chronic pain, ongoing and long-term management, the recognition of opioid use disorder, when to refer patients, how to taper opioids, and the importance of patient education and counseling. Eight questions addressing this core educational message were included in pretests for Programs 1 and 2 (Figure 6). Two of these questions were posed in both programs. In Program 1, 56\% of pretest participants recognized important aspects of monitoring, and two-thirds identified equivalent side effects of ER and IR opioids. Nearly $70 \%$ of participants selected the correct disposal of prescription 

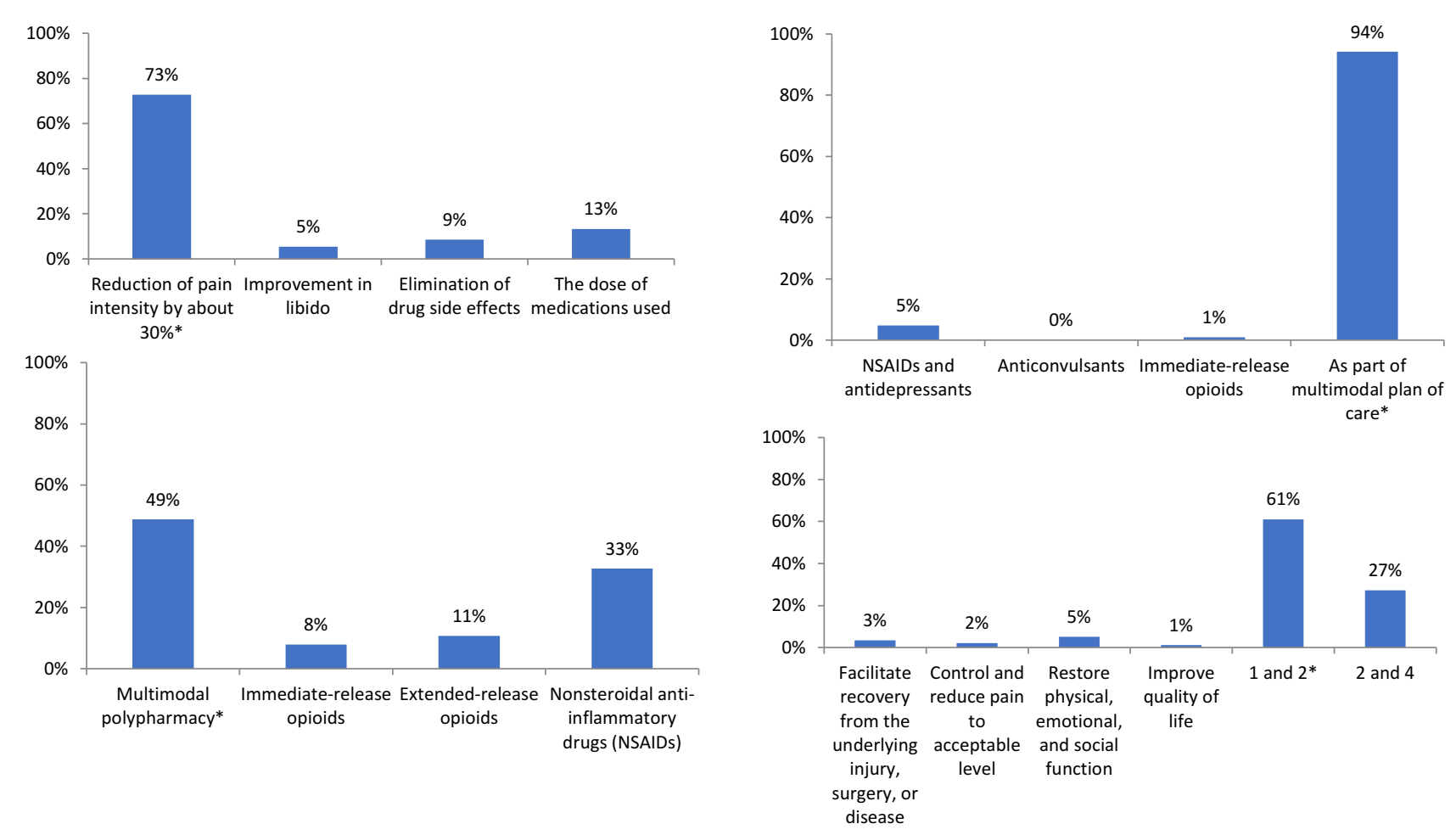

Figure 3 Pretest questions and responses for components of an effective treatment plan. (Correct answers are shown with an asterisk). Program I: Effective treatment of pain is determined by: $(n=3900)$. Program I: The most effective and safe way to manage pain with medication is: $(n=3900)$. Program 2: The most effective and safe way to manage pain with medication is: $(n=842)$. Program 2: The treatment goals associated with acute pain include: $(n=714)$.

\section{- Program 1 Program 2}

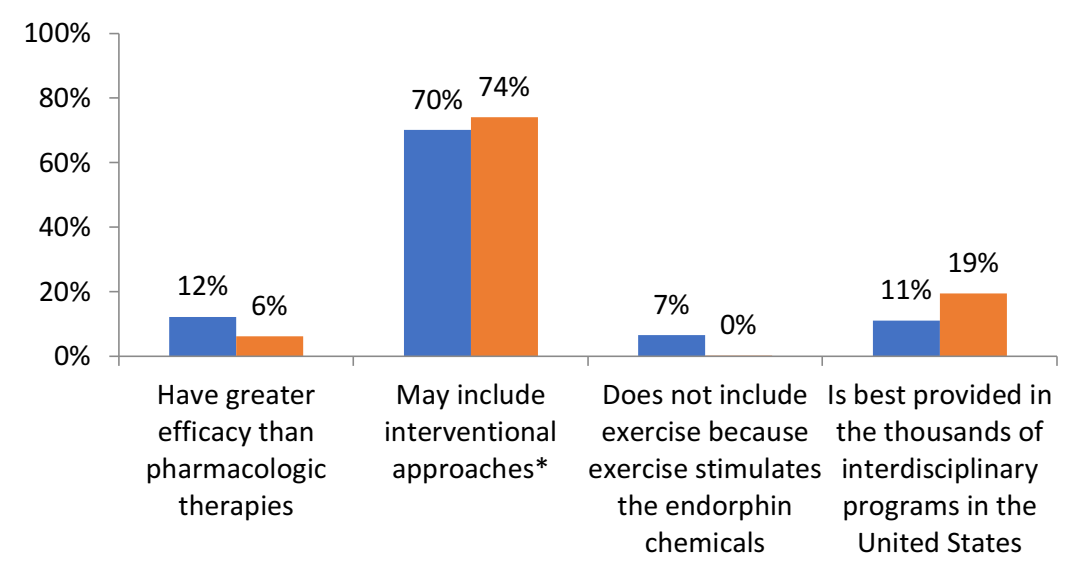

Figure 4 Pretest question and responses concerning nonpharmacologic approaches for pain. (Correct answer is shown with an asterisk). Programs I and 2: Nonpharmacologic therapies for pain: $(n=470 \mathrm{I})$.

opioids and advice to patients, and 70\% identified an indication for long-term opioid therapy. A minority, 31\%, recognized information on opioid potency. In Programs 1 and 2, most participants were neither knowledgeable of ER opioid conversion (34 and 44\%, respectively) nor recommended therapy when long-term opioid therapy is initiated $(20 \%$ and $25 \%$, respectively). In Program 2, 37\% recognized a nonrecommended counseling service during pain management.

\section{Addiction Education Primer}

The neurobiology of opioid use disorder (OUD), the use of screening tools to identify patients at risk, and the management of OUD are the chief components of the final core educational message of the 2018 FDA blueprint. In Program 1, only one-third of pretest participants identified useful screening tools for opioid misuse (Figure 7). A much larger percentage, however, recognized the 

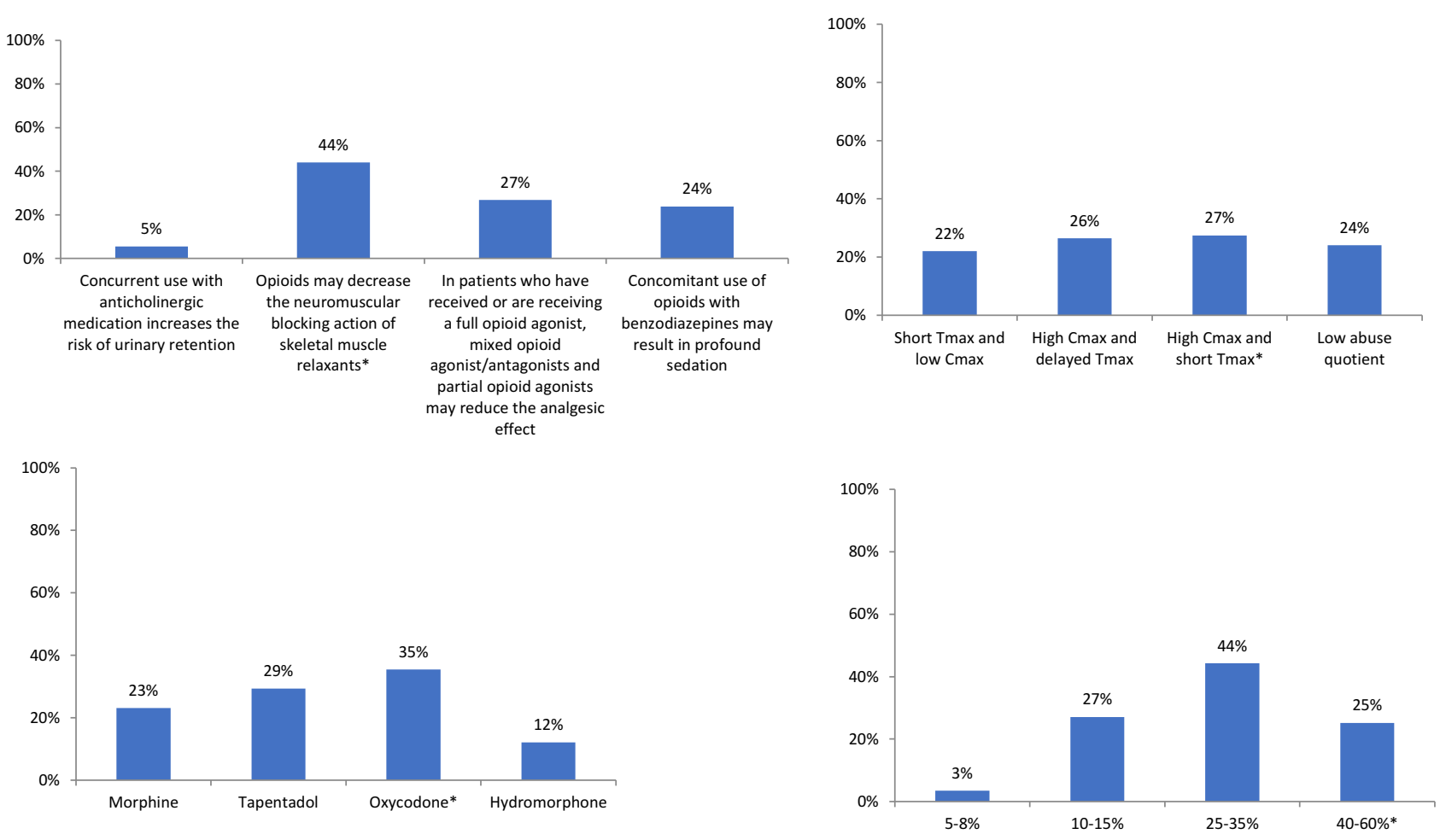

Figure 5 Pretest questions and responses addressing opioid and non-opioid analgesics. (Correct answers are shown with an asterisk). Program I: Which of the following statements regarding drug-drug interactions with opioids is FALSE? $(n=6050)$. Program I: The cytochrome P450 systems influence the metabolism of which of the following opioid analgesics? $(n=627)$. Program 2: Which pharmacokinetic properties contribute most to rewarding properties of a molecule? $(n=3900)$. Program 2: Looking at pharmacogenetic variability and response, what percentage of the general population has phenotype variability? $(n=901)$.

toxicity of methadone $(73 \%)$ and its intent to deter abuse (81\%). In Programs 1 and 2, 13\% and 57\%, respectively, identified features of opioid misuse/abuse. In Program 2, a considerable majority, 91\%, demonstrated knowledge of indications for take-home naloxone.

\section{Results of Pretest Self-Assessed Confidence}

Participants were asked to rate their confidence in their ability to employ patient-engagement techniques into pain management (Program 1) or develop a treatment plan for a patient with chronic pain (Program 2). In Program 1, nearly one-half (48\%) reported no or slight confidence (Figure 8). In Program 2, nearly three-quarters (73\%) reported no or slight confidence.

\section{Discussion}

We examined pretest $\mathrm{CME} / \mathrm{CE}$ responses of a participant audience consisting primarily of physicians (including $79 \%$ primary care), advanced practice nurses, and physician assistants and found substantial knowledge gaps in recommended pain management and opioid-related knowledge. Among the core messages of the 2018 FDA blueprint, gaps were most profound in pretest questions addressing definitions and mechanisms of pain, general principles of pharmacologic analgesic therapy, and certain aspects of managing patients on opioid analgesics and addiction education. Less profound gaps were identified in questions addressing components of an effective treatment plan and general principles of nonpharmacologic approaches. Participants demonstrated high pretest knowledge of questions addressing the assessment of patients in pain, particularly the importance of patient function and functional outcomes.

Among 5 similar or identical pretest questions posed in both programs, a substantially greater percentage of pretest participants in Program 2 recognized the utility of multimodal management (components of an effective treatment plan) and signs of aberrant behaviors (addiction education). However, participants in Program 1 and Program 2 showed little difference in knowledge gaps among questions addressing the use of interventional approaches (nonpharmacologic therapies for pain), the conversion of therapy from 1 ER opioid to another, and the initiation 

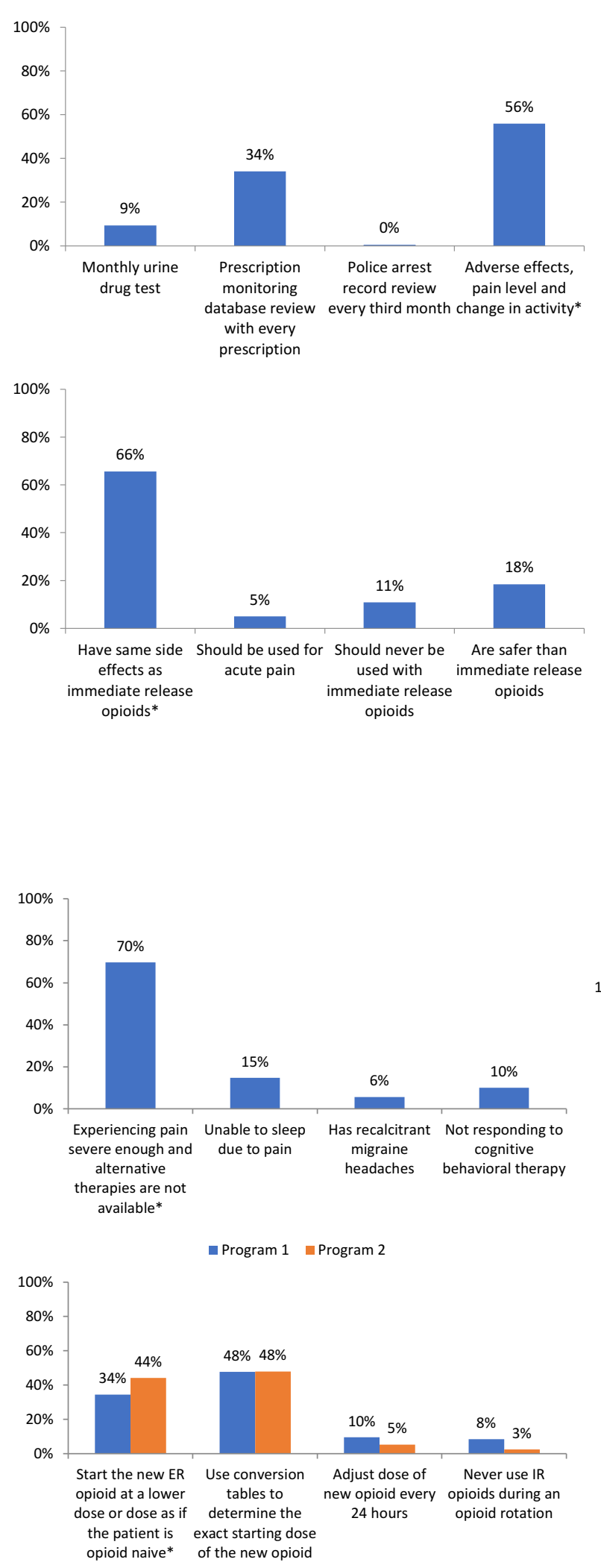
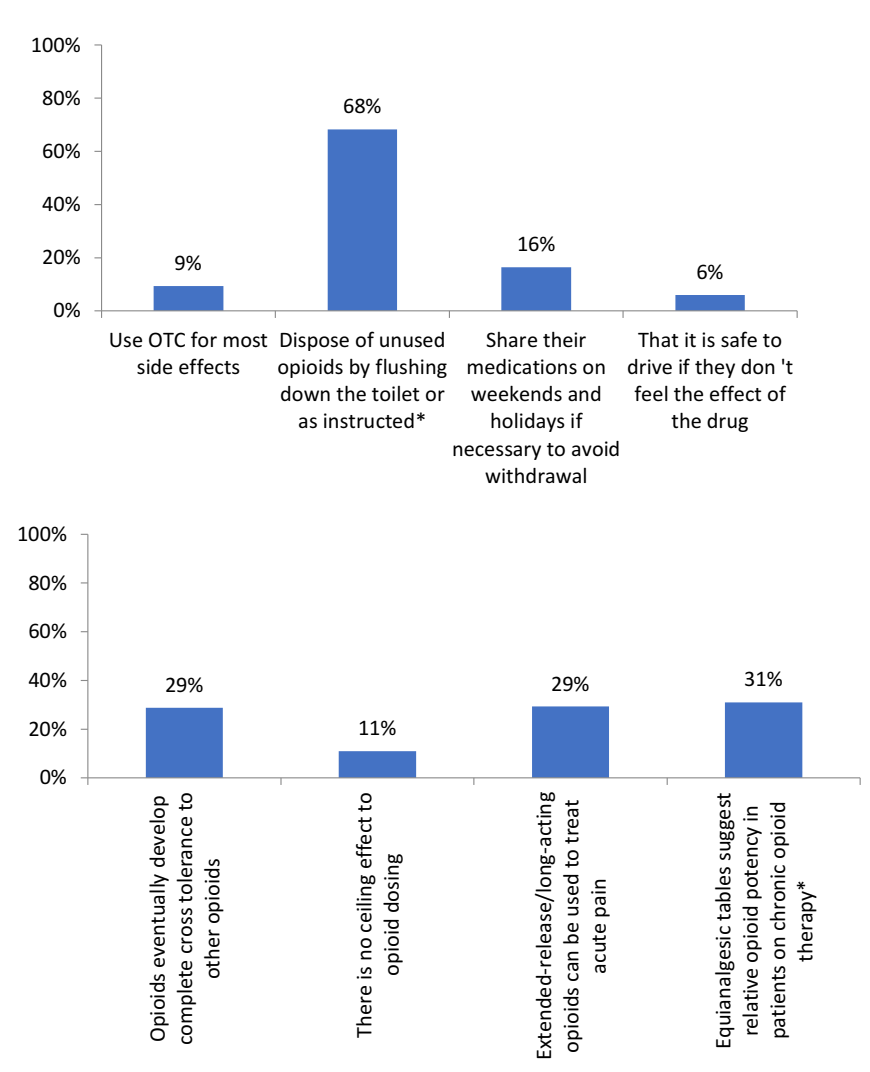

Figure 6 Pretest questions and responses concerning the prescription and management of opioid therapy. (Correct answers are shown with an asterisk). Program I: Monitoring patients on opioids should include: $(n=625)$. Program I: When counseling patients on the use of ER opioid formulations, which of the following is true? $(n=606)$. Program I: Physicians should counsel the caregivers or patients to: $(n=548)$. Program I: Upon considering the initiation of opioids, which of the following is true? $(n=45 \mathrm{I})$. Program I: Chronic opioid therapy is indicated when a patient is: $(n=3900)$. Programs I and 2: In converting patients from one ER opioid to another ER opioid: $(n=5394)$. Programs I and 2: When chronic opioid therapy is initiated: $(n=4702)$. Program 2: Patient/provider counseling strategies include all of the following except: $(n=787)$. 

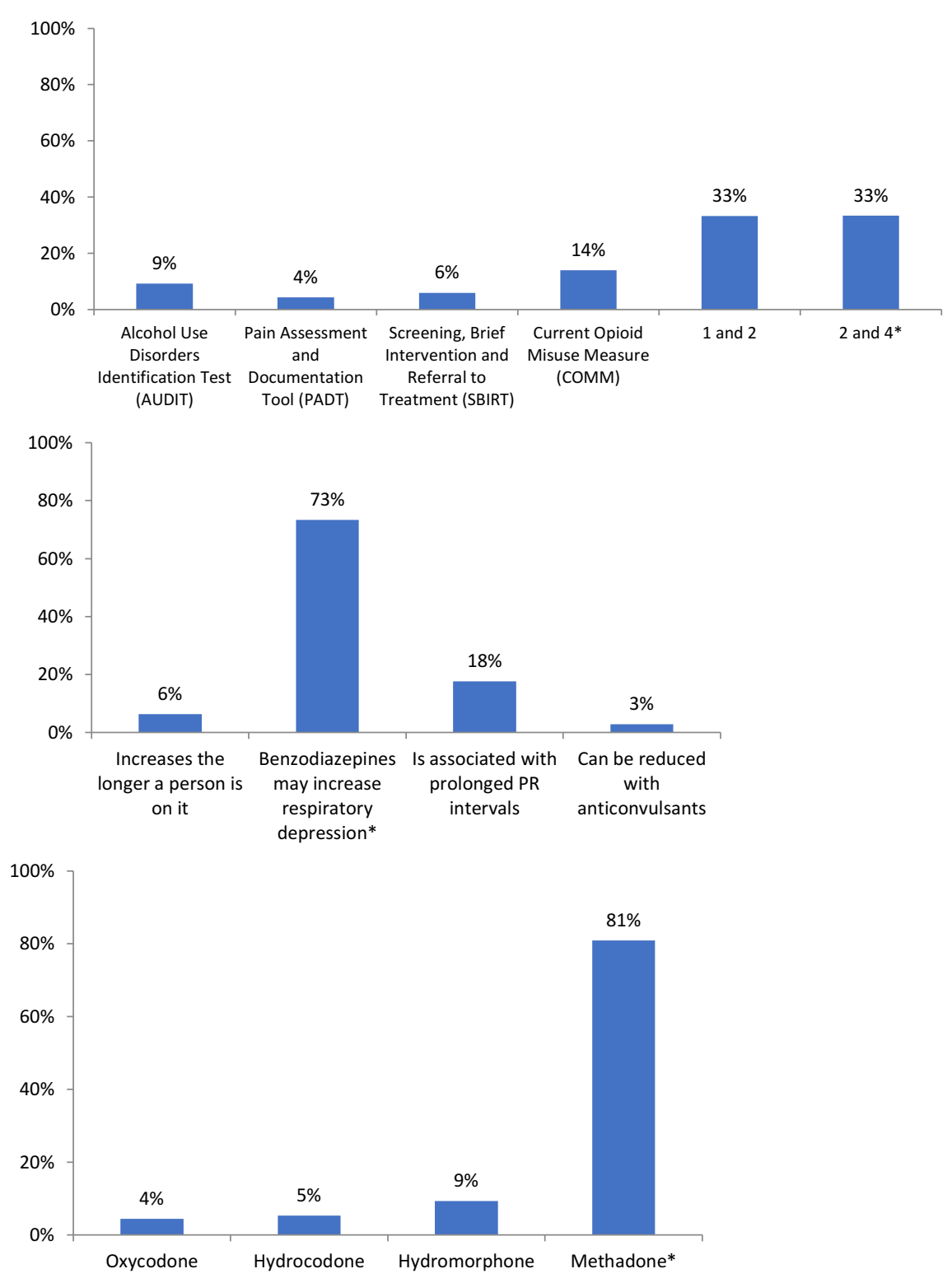

Figure 7 Continue.

of long-term opioid therapy (managing patients on opioid analgesics). These data overall suggest marginal improvement in primary care knowledge gaps between the publication of the 2016 and 2018 FDA blueprints. Self-rated confidence in aspects of pain management were low among participants in both programs.

Limitations of our analysis of pretest responses include the lack of a uniform group of participants between Program 1 and Program 2. Notably, a substantially greater percentage of physician participants $(90 \%)$ identified as primary care in Program 1. Also, the number of questions were limited in some 2018 FDA blueprint core message categories, which may have skewed the assessment of knowledge gaps and either overestimated or underestimated participants' knowledge. Likewise, question difficulty may have been uneven across FDA core message categories and therefore could have biased the identification of knowledge gaps.

Nevertheless, these data suggest considerable and persistent knowledge gaps in pain management and the use of opioid therapy, as well as limited confidence in pain management among practitioners. We see these data as evidence for the continued need for professional CME/CE education in pain management and as a guide for 
- Program 1 a Program 2

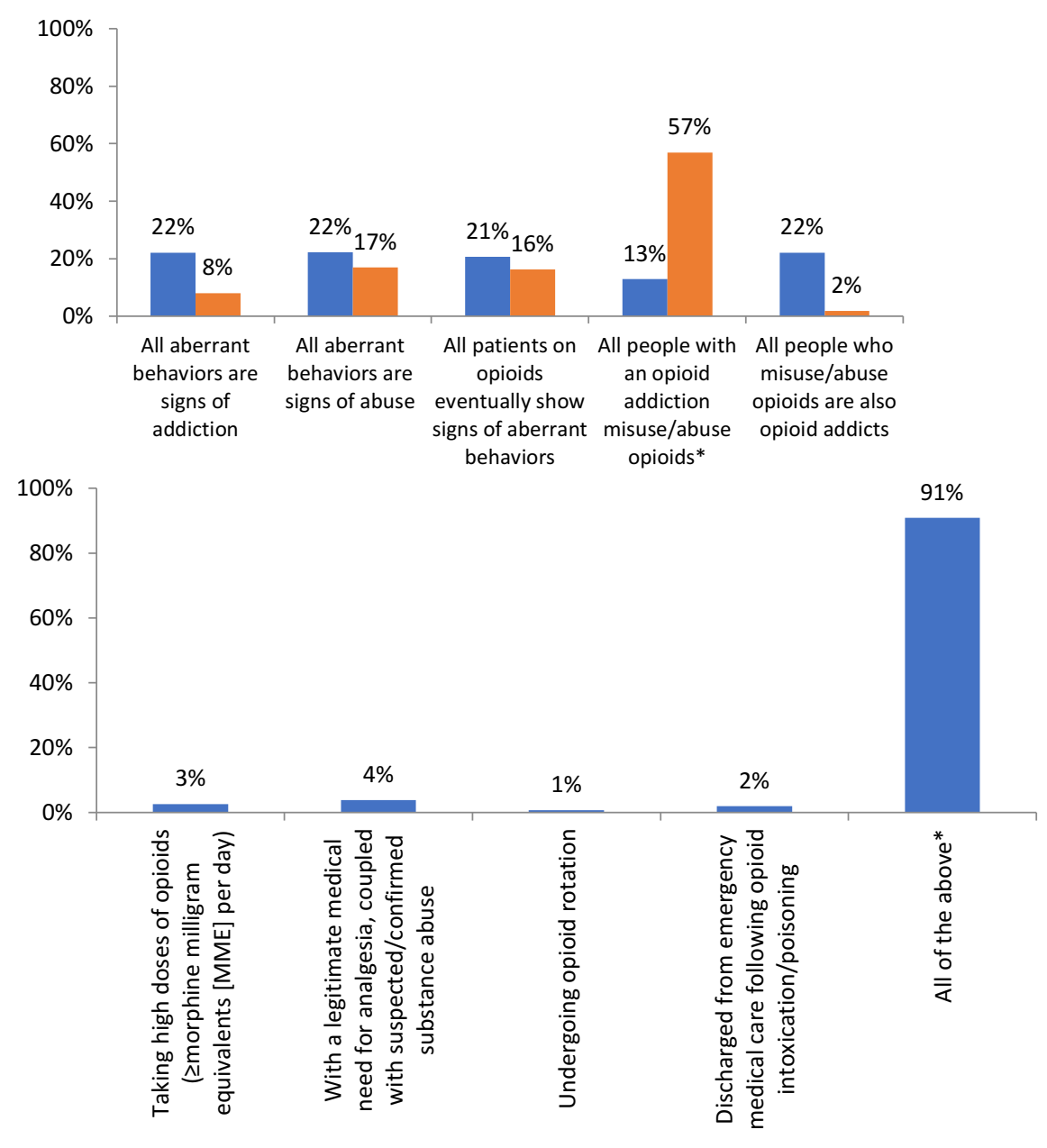

Figure 7 Pretest questions and responses concerning the identification and management of OUD and addiction. (Correct answers are shown with an asterisk). Program I: Which of the following screening tools is useful in identifying opioid misuse once therapy has begun? $(n=596)$. Program I: Toxicity of methadone: $(n=683)$. Program I: Examples of opioids that have been formulated to deter abuse include all of the following except? $(n=588)$. Programs I and 2: Which of the following is true? ( $n=4697)$. Program 2: Co-prescribing of take-home naloxone should be considered for patients: $(n=77)$.

emphasizing specific core messages of the 2018 FDA blueprint. Knowledge gaps requiring particular emphasis include the nature of chronic pain and pain definitions, opioid pharmacodynamics and pharmacokinetics, opioid conversion, the initiation of long-term opioid therapy, and the use of counseling services and abuse screening tools.

We also recognize that timely education on pain management and the use of opioids is even more imperative now due to the 2019 novel coronavirus disease (COVID19) pandemic. Experts anticipate that resultant lockdowns, diminished physical activity, and social isolation have contributed and will continue to contribute to stressors that prompt chemical coping and the relapse of substance abuse that leads to overdose deaths. ${ }^{13}$ Conversely risky opioid-seeking behaviors likely increase the probability of contracting COVID-19. Indeed, the CDC recently reported 81,000 drug-overdose deaths in the United States during the 12 months ending in May 2020. ${ }^{4}$ This is the highest number of overdose deaths recorded in a 12-month period, and these data further suggest a specific acceleration of overdose deaths during the early months of the pandemic. The primary drivers of these escalating overdose deaths appear to be due to the use of synthetic opioids, such as heroin, fentanyl (specifically illicit fentanyl), and their analogues. But we also know from recent historical data that prescription opioids make up a sizeable majority of opioid-related deaths. In response to the COVID-19related increase in overdose deaths, the CDC recommends the expanded distribution of naloxone, overdose- 

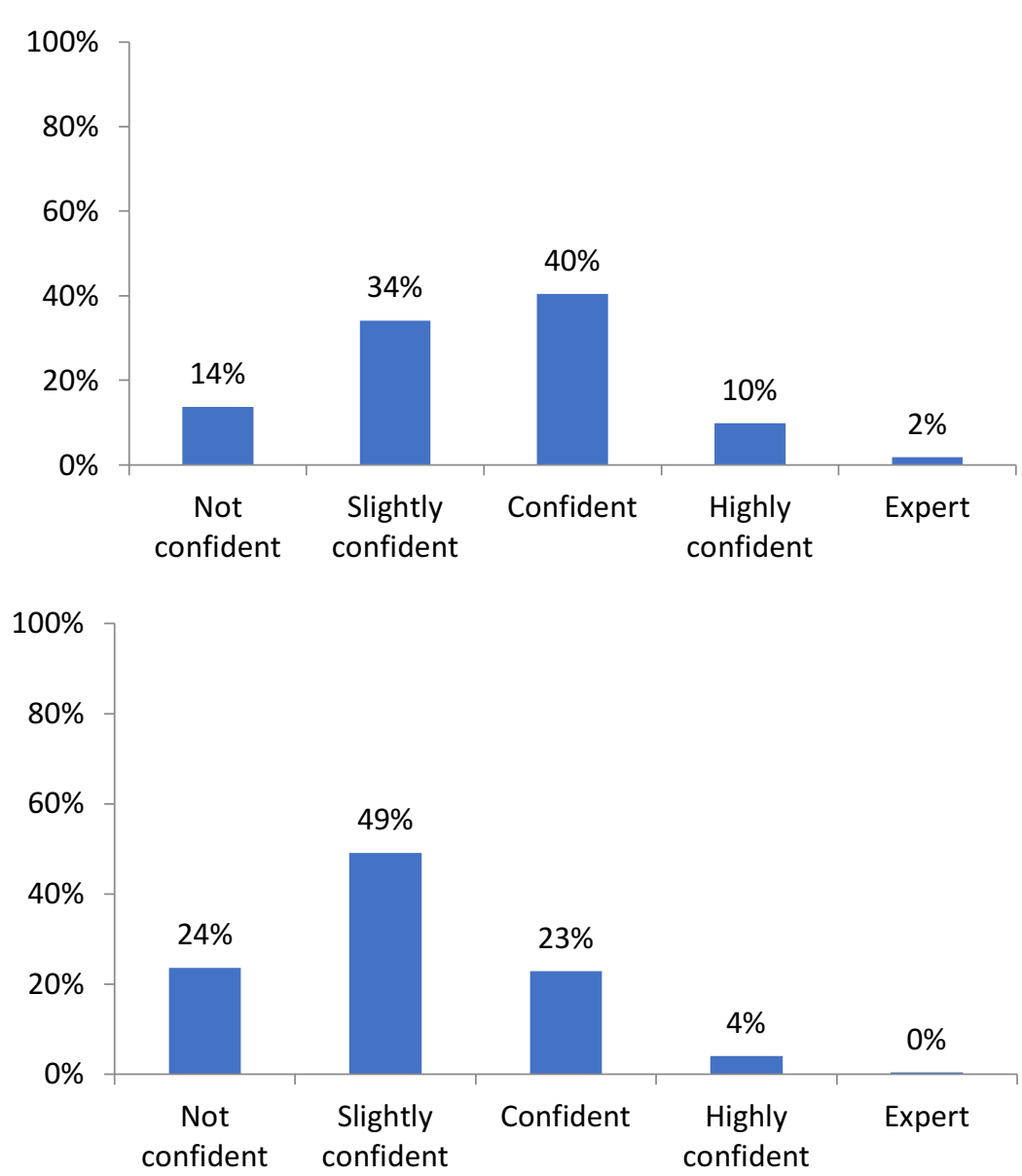

Figure 8 Pretest questions and responses regarding confidence in aspects of pain management. ( $\mathrm{N}$ values of pretest participants exceed those of $\mathrm{CME} / \mathrm{CE}$ completers) Program I: Please rate your confidence in your ability to employ patient engagement techniques into pain management. $(n=4569)$. Program 2: Please rate your confidence in your ability to develop a treatment plan for a patient with chronic pain. $(n=908)$.

prevention education, and awareness and access to treatment for substance use disorders. Our data, obtained before the COVID-19 pandemic, generally agree with these $\mathrm{CDC}$ recommendations, which heighten the acute need for ongoing $\mathrm{CME} / \mathrm{CE}$ programs on pain management and opioid use.

\section{Conclusion}

Pretest responses to $2 \mathrm{CME} / \mathrm{CE}$ programs that are based on the 2016 and 2018 FDA REMS blueprints for pain management and opioid use reveal substantial and persistent gaps in knowledge among clinicians, including primary care practitioners. Areas of particularly limited knowledge include the definitions and mechanisms of pain, general principles of pharmacologic analgesic therapy, and aspects of opioid analgesic therapy and addiction. Pretest participants also expressed limited confidence in their abilities to employ patient- engagement techniques into pain management or develop a treatment plan for a patient with chronic pain. These data support an ongoing need for comprehensive clinician-based education as outlined in the 2018 FDA blueprint. This educational need is made particularly acute by escalating overdose data during the COVID-19 pandemic.

\section{Funding}

The CME programs that are the sources of these data were funded by unrestricted educational grants from the REMS Program Companies (RPC).

\section{Disclosure}

Barbara J Martin reports personal fees from Rockpointe, during the conduct of the study. Charles Argoff lists advisory board member for BioDelivery Sciences International, Collegium Pharmaceutical, and Teva; speaker for Allergan and Teva. Bill McCarberg lists 
stockholder and consultant for Collegium Pharmaceutical and Johnson and Johnson; advisor for Lilly, Scilex, Averita; and speaker's bureau for Adapt and Scilex. Timothy Atkinson reports personal fees from Purdue Pharma LP, Rockpointe, axial Healthcare Inc, Auburn University, ASHP, and APhA, outside the submitted work. The authors report no other conflicts of interest in this work.

\section{References}

1. Centers for Disease Control and Prevention. Data Overview. The Drug Epidemic: Behind the Numbers. Available from: https://www.cdc.gov/ drugoverdose/data/. Accessed December 9, 2020.

2. National Institute on Drug Abuse. Opioid overdose crisis. Available from: https://www.drugabuse.gov/drug-topics/opioids/opioid-overdose -crisis. Accessed December 9, 2020.

3. Florence CS, Zhou C, Luo F, Xu L. The economic burden of prescription opioid overdose, abuse, and dependence in the United States, 2013. Med Care. 2016;54(10):901-906. doi:10.1097/ MLR.0000000000000625

4. CDC. Overdose deaths accelerating during COVID-19. Available from: https://www.cdc.gov/media/releases/2020/p1218-overdosedeaths-covid-19.html. Accessed December 23, 2020.

5. Morone NE, Weiner DK. Pain as the fifth vital sign: exposing the vital need for pain education. Clin Ther. 2013;35(11):1728-1732. doi:10.1016/j.clinthera.2013.10.001
6. Van Zee A. The promotion and marketing of OxyContin: commercial triumph, public health tragedy. Am J Public Health. 2009;99 (2):221-227. doi:10.2105/AJPH.2007.131714

7. Phillips DM. JCAHO pain management standards are unveiled. Joint Commission on Accreditation of Healthcare Organizations. JAMA. 2000;284(94):428-429. doi:10.1001/jama.284.4.423b

8. United States Congress. HR 3244. Decade of pain control and research; January 1, 2001.

9. Guy GP Jr, Zhang K. Opioid prescribing by specialty and volume in the US. Am J Prev Med. 2018;55(5):e153-e155. doi:10.1016/j. amepre.2018.06.008

10. Kiang MV, Humphreys K, Cullen MR, Basu S. Opioid prescribing patterns among medical providers in the United States, 2003-17: retrospective, observational study. BMJ. 2020;29(368):16968. doi:10.1136/bmj.16968

11. Food and Drug Administration. FDA blueprint for prescriber education for extended-release and long-acting opioid analgesics; August, 2016.

12. Food and Drug Administration. FDA education blueprint for health care providers involved in the treatment and monitoring of patients with pain; September, 2018. Available from: https://www.fda.gov/ media/99496/download. Accessed December 9, 2020.

13. Mallet J, Dubertret C, Le Strat Y. Addictions in the COVID-19 era: current evidence, future perspectives a comprehensive review. Prog Neuropsychopharmacol Biol Psychiatry. 2021;106:110070. doi:10.1016/j.pnpbp.2020.110070
Journal of Pain Research

\section{Publish your work in this journal}

The Journal of Pain Research is an international, peer reviewed, open access, online journal that welcomes laboratory and clinical findings in the fields of pain research and the prevention and management of pain. Original research, reviews, symposium reports, hypothesis formation and commentaries are all considered for publication. The manuscript

\section{Dovepress}

management system is completely online and includes a very quick and fair peer-review system, which is all easy to use. Visit http:// www.dovepress.com/testimonials.php to read real quotes from published authors. 